\title{
An Examination of "Nonleadership": From Laissez-Faire Leadership to Leader Reward Omission and Punishment Omission
}

\author{
Timothy R. Hinkin \\ Cornell University \\ Chester A. Schriesheim \\ University of Miami
}

\begin{abstract}
Laissez-faire leadership has received much less attention than have the 3 transactional leadership dimensions of the Multifactor Leadership Questionnaire (MLQ). However, laissez-faire leadership has shown strong negative relationships with various leadership criteria, and the absence of leadership (laissez-faire leadership) may be just as important as is the presence of other types of leadership. This article focuses on a single type of laissez-faire leadership (i.e., the lack of response to subordinate performance). Using a reinforcement perspective, the authors developed measures and examined the effects of the lack of performance-contingent reinforcement in 2 forms: reward omission (leader nonreinforcement of good subordinate performance) and punishment omission (leader nonreinforcement of poor subordinate performance). They found strong evidence in support of the construct validity of the new measures and found that omission was related to follower satisfaction with the leader, subordinate-rated leader effectiveness, subordinate-perceived role clarity, and supervisor-rated subordinate performance.
\end{abstract}

Many approaches to the study of leadership exist (see Bass, 1990; Yukl, 2006) but, according to Judge and Piccolo (2004), "transformational-transactional leadership theory dominates current thinking about leadership research" (p. 762). Although the study of transformational leadership is certainly not new (see House, 1977), the publication of Bass's original theory (Bass, 1985) and the development of the Multifactor Leadership Questionnaire (MLQ) appear to have stimulated the majority of recent research in this area (Hunt, 1999; Yukl, 2006).

To examine eight leadership dimensions that constitute what is now called the "full range leadership theory" (Antonakis, Avolio, \& Sivasubramaniam, 2003; Avolio \& Bass, 1991; Bass \& Avolio, 1997), Bass and his associates (e.g., Bass \& Avolio, 1993, 1997) developed Form 5X of the MLQ. The MLQ-5X contains four scales that are designed to measure aspects of transformational leadership. The scales include Idealized Influence, Individualized Consideration, Intellectual Stimulation, and Inspirational Motivation. The MLQ-5X also contains three scales that assess transactional leadership; these scales are Contingent Reward, Active Management by Exception, and Passive Management by Exception. One scale measuring nonleadershipLaissez-Faire Leadership -is part of the MLQ-5X (Antonakis et al., 2003; Bass \& Avolio, 1997).

Bass and his colleagues have argued that transactional leadership is a necessary precondition if transformational leadership is to be effective (Avolio, 1999). By providing direction and focus, transactional leadership makes the use of transformational behaviors less confusing and ambiguous. From a somewhat different perspective, Podsakoff, Bommer, Podsakoff, and MacKenzie (2006) seem to agree with this 
assessment and further suggest that "leader reward and punishment behavior is . . . the heart of what is called transactional leadership" (p. 114).

As measured by the MLQ, leader contingent reward behavior involves leaders clarifying expectations and providing rewards when subordinate performance warrants them. Active management by exception involves leaders monitoring follower performance and administering some form of intervention (e.g., punishment) when poor performance is found, and passive management by exception involves leaders waiting until problems become apparent before they take action. The MLQ Contingent Reward scale has shown strong positive relationships with subordinate perceptions of leader effectiveness and satisfaction with the leader ( $r s=.45-.55$ ), whereas active management by exception has shown mild positive relationships ( $r s=.13-.24)$. In contrast, passive management by exception has shown mild negative relationships ( $r s=-.14$ to -.27 ) with the same variables (Judge \& Piccolo, 2004).

In contingent reward and active and passive management by exception, the leader intervenes in response either to good or to poor performance (Tejeda, Scandura, \& Pillai, 2001). However, unlike these three transactional leadership dimensions, laissez- faire leader behavior is not related to follower performance. Rather, it is characterized by avoiding decisions, hesitating to take action, and being absent when needed. Judge and Piccolo (2004) found that MLQ laissez-faire leadership had strong significant negative correlations with leader effectiveness $(r=-.54)$ and satisfaction with the leader $(r=-.58)$ and concluded that "the absence of leadership (laissez-faire leadership) is nearly as important as the presence of other forms of leadership" (p. 765). In a more recent empirical study, Skogstad, Einarsen, Torsheim, Aasland, and Hetland (2007) agreed with this assertion and concluded that "laissez-faire leadership behavior is a destructive leadership behavior" (p. 80) that warrants much more future research.

Broad and global in nature, the MLQ laissez-faire measure consists of several types of nonleadership (i.e., avoiding responsibility, not responding to problems, being absent when needed, failing to follow up, resisting expressing views, and delaying responses). It is unclear, as a result of this multidimensionality, which subtypes of laissez-faire behavior may have the greatest impact on subordinates. Perhaps not surprisingly, Judge and Piccolo (2004) recommended that laissez-faire behavior be studied in more depth and suggested that transactional leadership be envisioned as a continuum, with contingent reward behavior on one end and laissez-faire leadership on the other. (Active management by exception and passive management by exception would then be positioned between the two ends of the continuum.)

Although the data suggest that the negative effects of nonleadership are substantial, the literature on laissez-faire leadership is sparser than the literature on other MLQ dimensions (Dumdum, Lowe, \& Avolio, 2002; Lowe, Kroeck, \& Sivasubramaniam, 1996). For example, in their recent meta-analysis, Judge and Piccolo (2004) found 73 studies of contingent reward, 53 studies of active management by exception, 40 studies of passive management by exception, and only 26 studies of laissez-faire leadership. In very few of these studies was laissez-faire the focal variable of interest or the subject of any theoretical development. As the primary responsibilities of a leader include monitoring and responding to the performance of subordinates (Yukl, 2006), it is unfortunate that so little theory and research has focused on laissez-faire leadership. Research strongly supports the idea that behavior is a function of its consequences (Luthans \& Kreitner, 1985). If a leader provides no response to the performance of followers, their performance may be controlled by factors other than the leader and may therefore be unacceptable or inconsistent. Given these facts, it seemed appropriate for us to explore inactive leadership from both theoretical and empirical perspectives. In this article, therefore, we adopt a reinforcement approach and introduce the concepts of 
leader reward omission and punishment omission, leader nonresponse to good and poor subordinate performance, respectively.

\section{Reward Omission and Punishment Omission}

The major defining characteristic of laissez-faire leadership as measured by the MLQ is the lack of leader response to a variety of potential stimuli in a variety of situations. Laissez-faire leadership does not appear to be motivated and intentional; it is simply the lack of any response to subordinates' needs and performance. In an attempt to understand inactive or nonresponsive leadership, we focus on the lack of leader responses to one particular stimulus, subordinate performance, both good and poor (which we call reward omission and punishment omission, respectively). We believe that nonresponse to good and poor performance will produce both important and different effects.

Komaki (1998) noted that nonresponse to undesired behavior (i.e., punishment omission) has not been considered in organizational research; nevertheless, it has strong effects and should be examined. The same can be said for the nonreinforcement of desired behavior (i.e., reward omission). For example, in a series of laboratory experiments, Pithers (1985) found that the lack of appropriate reinforcement following a desired behavior resulted in a decline in performance over time; this nonreinforcement was termed omission conditioning. When this finding is extrapolated to an organizational setting, failure to reinforce desired subordinate performance is a form of omission conditioning and clearly is not a desirable leadership behavior. A leader who withholds reinforcement, whether intentionally or unintentionally, may very well produce negative consequences, particularly when subordinate performance is high (subordinate performance would be expected to decline). On the other hand, proponents of "OB mod" (organizational behavior modification; e.g., Luthans \& Kreitner, 1985) have argued that nonresponse to poor subordinate performance may not extinguish the undesirable behavior and will do nothing to elicit the desired behavior (Petrock, 1978).

Nonresponse to good performance is likely to have more negative effects than will nonresponse to poor performance. These effects can be explained with attribution theory (Weiner, 1985), equity theory (Adams, 1965), and the organizational justice literature (e.g., Byrne \& Cropanzano, 2001; Thibaut \& Walker, 1975). Attributions can be made to an external source of responsibility, outside the individual's control, or to an internal source, within the individual's control.

On the basis of attribution theory, poor subordinate performance is likely to be attributed by the subordinate to environmental factors beyond his or her control. Consequently, leader nonresponse would probably be seen as equitable or fair, because the subordinate would most likely not feel responsible for the poor performance. Subordinate affective reactions to punishment omission should therefore be neutral (or, at most, mildly positive), and subordinate performance would be expected to be unaffected. This is so because the undesirable behavior (poor performance) may be under the control of reinforcements administered by a source other than the supervisor and therefore is likely to continue (Petrock, 1978). Additionally, the lack of supervisor response to poor subordinate performance may not be associated with job dissatisfaction, because the subordinate may not expect reinforcement when performance is poor (cf. Locke, 1976).

Current leader reinforcement approaches seem to predict that nonreinforced subordinate good performance will lead to negative subordinate affective and behavioral responses (e.g., dissatisfaction and decreases in performance; Howell \& Costley, 2006; Komaki, 1998). An explanation for this prediction is that 
good subordinate performance is likely to be attributed by the subordinate to his or her own effort and ability. Thus, a nonresponse is more likely to be seen as inequitable or unfair, as the subordinate would feel responsible and deserving of rewards for the good performance. Furthermore, expectancy theory suggests that if the link between the performance of the individual and the outcomes he or she receives is missing, subsequent motivation will decline over time (Vroom, 1964). Subordinate reactions to a leader's nonresponse to good performance should therefore be moderately to strongly negative, both in terms of affective (e.g., job satisfaction) and behavioral (e.g., motivation and job performance) responses. Additionally, both types of nonreinforcement might very well result in role ambiguity or confusion about job expectations on the part of subordinates (Rizzo, House, \& Lirtzman, 1970).

As shown in Table 1, probable leader responses to good subordinate performance can be conceptualized as varying from contingent

Table 1

A Revised Conceptualization of Likely Leader Performance-Related Reinforcement

\begin{tabular}{clll}
\hline & \multicolumn{3}{c}{ Leader's response } \\
\cline { 2 - 3 } Subordinate's performance & \multicolumn{1}{c}{ Negative stimuli } & Neutral stimuli & Positive stimuli \\
\hline \multirow{2}{*}{$\begin{array}{l}\text { Good } \\
\text { Poor }\end{array}$} & $\begin{array}{l}\text { Reward omission } \\
\text { Cunishment omission }\end{array}$ & Contingent reward \\
& $\begin{array}{l}\text { Active management by exception } \\
\text { Passive management by exception }\end{array}$ & & \\
& & & \\
\hline
\end{tabular}

Note. Reward omission refers to leader nonreinforcement of subordinate good performance; contingent reward refers to leader administration of rewards following subordinate good performance; contingent punishment refers to leader administration of punishments following subordinate poor performance; active management by exception refers to leader monitoring of subordinate performance and intervention when poor performance occurs; passive management by exception refers to leader nonmonitoring of subordinate performance and intervention when poor performance is discovered; punishment omission refers to leader nonreinforcement of subordinate poor performance.

reward to reward omission; probable leader responses to poor subordinate performance can range from active and passive management by exception and contingent punishment to punishment omission. Laissezfaire leadership, which is generally nonresponsive, is not included in Figure 1 but can be seen as a neutral stimulus that occurs under both good and poor subordinate performance. We believe that this figure more fully represents the spectrum of likely performance- related transactional leader behaviors than does the continuum suggested by Judge and Piccolo (2004).

The above discussion suggests that researchers could profitably sharpen our conceptualization of inactive leadership by considering what we call "reward omission" and "punishment omission." Therefore, our purposes in this study are as follows: (a) to present a conceptualization of typical leader reinforcement behavior as falling on a performance-related continuum that ranges from nonreinforcement to the provision of a high degree of performance- contingent reinforcement; (b) to develop and assess the construct validity of scales that measure the two types of omission; and (c) to test the new scales for concurrent and predictive validity and for an "augmentation effect" beyond the effects of existing MLQ measures, using a 
set of meaningful dependent variables (including variables that have been examined in prior MLQ studies).

There are a number of ways to examine the issue of whether the two types of perceived leader omission are meaningful constructs. We conducted four separate studies. In the first study, we conducted a content adequacy assessment to determine if the two constructs were theoretically independent from laissez-faire leadership and management by exception. In Study 2, we conducted confirmatory factor analyses to examine the discriminant validity of the new measures. In Study 3, we used correlation and hierarchical regression analysis to determine whether support for the omission constructs could be obtained with MLQ laissez-faire and transactional leadership dimensions as well as three dependent variables. Finally, in Study 4, we employed correlation analysis to examine the usefulness of leader reward and punishment omission in "predicting" subsequent subordinate job performance.

\section{Study 1: A Test of Content Validity}

Because it was necessary (for construct validity purposes) to demonstrate that our two new omission constructs (and their operationalizations) were theoretically different from similar existing constructs (Nunnally \& Bernstein, 1994), we examined content validity employing the active and passive management by exception and laissez-faire leadership measures of the MLQ. Although active and passive management by exception may appear somewhat similar, factor analytic research suggests that they are perceived as separate constructs by respondents. However, laissez- faire leadership has been perceived as being similar to passive management by exception; these two leadership styles have had consistently strong intercorrelations and have sometimes formed a single passive leadership dimension in studies that used factor- analytic techniques (Avolio, Bass, \& Jung, 1999; Den Hartog, Van Muijen, \& Koopman, 1997; Druskat, 1994). Laissez-faire leadership also has had relationships with dependent variables that are generally negative, like those of passive management by exception, except that they have been stronger (Bass, Avolio, Jung, \& Berson, 2003).

Two explanations seem most plausible for the consistent and strong relationship that exists between laissez-faire leadership and passive management by exception. First, managers who tend to use passive management by exception also use laissez-faire leadership (so the behaviors covary in tandem). Second, respondents may have a difficult time distinguishing between the two constructs (i.e., the MLQ items measuring the two constructs are seen as tapping the same domain or construct). Thus, with the passive management by exception and laissez-faire measures, one important question is whether the MLQ items theoretically represent two different constructs or a single construct or, in other words, whether the passive management by exception and laissez-faire dimensions are content valid. For leader reward omission and punishment omission, one would hope that any items developed to measure these constructs would be seen as theoretically and empirically distinct from each other and from passive management by exception and laissez-faire leadership. The reason for concern about distinctiveness from passive management by exception and laissez-faire leadership is that these two dimensions assess aspects of inactive leadership and may therefore be confused with leader behavior that does not reward good or punish poor performance.

Schriesheim, Powers, Scandura, Gardiner, and Lankau (1993) and Schriesheim, Cogliser, Scandura, Lankau, and Powers (1999) have 
argued that "content adequacy" (content validity) is an important first step in the construct validation process and that content adequacy should be assessed immediately after a measure has been developed but prior to its utilization in a research study. In Study 1, we conduced a content adequacy assessment using an analysis of variance technique developed by Hinkin and Tracey (1999). The analysis of variance (ANOVA) technique eliminates the use of subjective judgment for item retention; ANOVA provides a direct empirical test for determining item distinctiveness. Additionally, ANOVA is very simple and straightforward. Finally, this technique can be utilized with small sample sizes and allows researchers to address both practical and statistical differences (see Cohen, 1969; Hinkin \& Tracey, 1999).

When this assessment procedure is employed, items from similar yet different measures are presented to respondents along with theoretical definitions of each of the constructs. In this case, we used the MLQ-5X (Bass \& Avolio, 1993) passive management by exception and laissez-faire items, in addition to items measuring leader reward and punishment omission. The reward omission items included two items from the Contingent Reward subscale of the Leader Reward and Punishment Questionnaire (LRPQ; Podsakoff et al., 2006; Podsakoff, Todor, Grover, \& Huber, 1984; Podsakoff, Todor, \& Skov, 1982). These were reverse-scored Contingent Reward Items 09 and 10: "My good performance often goes unacknowledged by my supervisor" and "I often perform well in my job and still receive no praise from my supervisor." These two items have been shown to be problematic, as they have not loaded on their appropriate factors in a multisample assessment of LRPQ validity (Schriesheim, Hinkin, \& Tetrault, 1991). We developed four additional reward omission items and six additional punishment omission items in a deductive manner, in that we began with the theoretical definitions and then created items that were conceptually consistent with the definitions.

\section{Sample and Procedure}

Sample. The sample consisted of $62 \mathrm{MBA}$ students at a medium-sized university in the southern United States. Of those sampled, the average age was 29 years and 69\% were male. As noted in Schriesheim and associates (Schriesheim et al., 1993, 1999), the two fundamental requirements for individuals participating in this task are sufficient intellectual ability to rate the items and a lack of any theoretical biases. We considered graduate students appropriate subjects for this task. Questionnaires that took approximately 15 minutes to complete were administered during normal class time. Explicit written and verbal instructions were provided prior to administration, and the responses were anonymous.

Procedure. The respondents rated each of the 27 items ( 7 passive management by exception, 8 laissez-faire, 6 reward omission, and 6 punishment omission) on the extent to which they believed the item was consistent with each of the four theoretical definitions. Response choices ranged from 1 (not at all) to 5 (completely). Each rating form consisted of four pages plus a cover page of instructions and examples (see Schriesheim et al., 1993, 1999, for illustrations). The definition of one of the four behaviors was presented at the top of each separate page and was followed by a randomized listing of all the items. We took extreme care to ensure that the definitions accurately described each different behavior and that the passive management by exception and laissez-faire definitions were consistent with Bass and Avolio's (1993) conceptualization. The definitions used were as follows:

Reward omission: Managers do not respond to what a subordinate perceives to be his or her good performance.

Punishment omission: Managers do not respond to what a subordinate perceives to be his or her 
poor performance.

Passive management by exception: Managers intervene only after noncompliance has occurred or when mistakes have already happened.

Laissez-faire leadership: Managers avoid making decisions, abdicate responsibility, and do not use their authority.

See the Appendix for the omission items; the full set of the MLQ-5X items employed cannot be reproduced, due to copyright restrictions. However, three of these items are presented below. We administered two versions of the questionnaire, with the items and pages in a different order, to control for order effects. No statistically significant differences were found in responses across the two versions.

\section{Methods of Analysis}

In the first step of the ANOVA procedure, we calculated the mean score for each item on each of the four leadership dimensions. Then, we conducted a comparison of means for each item across the four dimensions using one-way analysis of variance and Duncan's multiple range test. This allowed us to identify those items that were evaluated appropriately (i.e., to identify items that were statistically significantly higher $[p<.01]$ on the appropriate dimension versus the other dimensions).

\section{Results}

The results from this analysis revealed that some of the 27 items were not classified correctly. Of the 15 MLQ items, 3 were misclassified. However, all 12 of the omission items were classified appropriately, and this provides evidence of their content validity. Table 2 presents the results of the analyses.

One of the misclassified MLQ items, MBEP-4 ("My manager tells me what I've done wrong rather than what I've done right"), was classified as assessing leader reward omission and passive management by exception. ${ }^{1}$ MBEP-6 ("My manager shows he/she is a firm believer in 'If it ain't broke, don't fix it") was classified as assessing both punishment omission and passive management by exception. Finally, LF-2 ("My manager takes no action even when problems become chronic") was classified as indicative of leader punishment omission, in addition to laissez-faire leadership. However, the remainder of the MLQ items (12 of 15) were classified correctly, which provided evidence of their content validity.

\footnotetext{
1 Multifactor Leadership Questionnaire Items 10 (LF-2), 28 (MBEP-4), and 44 (MBEP-6) are from Multifactor Leadership Questionnaire (pp.1-2), by B. M. Bass and B. J. Avolio, 1993, Palo Alto, CA: Consulting Psychologists Press. Copyright 1991 by Bernard M. Bass and Bruce J. Avolio. Reprinted with permission.
} 


\begin{tabular}{lcccc}
\hline $\begin{array}{c}\text { Item } \\
\text { number }\end{array}$ & $\begin{array}{c}\text { Reward } \\
\text { omission }\end{array}$ & $\begin{array}{c}\text { Punishment } \\
\text { omission }\end{array}$ & $\begin{array}{c}\text { Passive management } \\
\text { by exception }\end{array}$ & Laissez-faire \\
\hline RO-1 & $\mathbf{4 . 2 1}$ & 2.61 & 2.95 & 3.07 \\
RO-2 & $\mathbf{4 . 0 0}$ & 2.73 & 3.08 & 3.36 \\
RO-3 & $\mathbf{4 . 2 3}$ & 2.84 & 3.18 & 3.38 \\
RO-4 & $\mathbf{4 . 1 8}$ & 2.76 & 3.00 & 3.15 \\
RO-5 & $\mathbf{4 . 1 8}$ & 2.76 & 3.05 & 3.02 \\
RO-6 & $\mathbf{4 . 0 5}$ & 2.66 & 3.00 & 3.28 \\
PO-1 & 2.03 & $\mathbf{3 . 5 5}$ & 1.98 & 2.82 \\
PO-2 & 2.13 & $\mathbf{3 . 6 3}$ & 2.19 & 3.02 \\
PO-3 & 1.97 & $\mathbf{3 . 6 6}$ & 1.95 & 2.80 \\
PO-4 & 1.97 & $\mathbf{3 . 8 2}$ & 1.94 & 2.93 \\
PO-5 & 1.97 & $\mathbf{3 . 7 9}$ & 1.85 & 2.89 \\
PO-6 & 2.15 & $\mathbf{3 . 8 2}$ & 2.21 & 3.02 \\
MBEP-1 & 2.42 & 2.58 & $\mathbf{4 . 1 5}$ & 2.97 \\
MBEP-2 & 2.48 & 2.65 & $\mathbf{3 . 6 6}$ & 2.80 \\
MBEP-3 & 2.32 & 2.73 & $\mathbf{3 . 7 7}$ & 3.05 \\
MBEP-4* & 3.52 & 2.29 & 3.48 & 2.28 \\
MBEP-5 & 2.35 & 2.52 & $\mathbf{3 . 8 7}$ & 2.67 \\
MBEP-6* & 2.61 & 3.82 & 3.50 & 3.23 \\
MBEP-7 & 2.23 & 2.69 & $\mathbf{3 . 6 5}$ & 2.84 \\
LF-1 & 2.23 & 2.60 & 2.44 & $\mathbf{3 . 4 1}$ \\
LF-2* & 1.90 & 3.21 & 2.18 & 3.34 \\
LF-3 & 2.37 & 2.60 & 2.48 & $\mathbf{3 . 2 8}$ \\
LF-4 & 2.48 & 2.69 & 2.58 & $\mathbf{3 . 3 0}$ \\
LF-5 & 2.48 & 2.53 & 2.34 & $\mathbf{3 . 4 1}$ \\
LF-6 & 2.26 & 2.55 & 2.40 & $\mathbf{3 . 4 3}$ \\
LF-7 & 2.35 & 2.69 & 2.56 & \\
LF-8 & 2.23 & 2.61 & 2.44 & \\
\hline & & & & $\mathbf{3 . 6 2}$ \\
\hline
\end{tabular}

Note. Items were randomized for survey administration. Boldface type denotes a significantly higher $(p<.01)$ mean score. An asterisk and italic type denote item means that were not significantly higher on the appropriate definition. $\mathrm{LF}=$ laissez-faire; $\mathrm{RO}=$ reward omission; $\mathrm{PO}=$ punishment omission; MBEP = management by exception—passive.

As suggested in Hinkin (1998), one should create more items than would be used in the final scales when testing the psychometric properties of a measure (in case some of the items are not classified correctly). Because we were striving for parsimony (as well as adequate item content), we wanted to create measures with four items per dimension for future research. Consequently, we used the four items that had the highest mean scores on their appropriate dimensions as the best representations of omission in our subsequent analyses. The Appendix contains both the full and retained sets of omission items.

\section{Study 2: A Factor-Analytic Test of Discriminant Validity}

Although we have advanced the argument that reward omission and punishment omission are most 
similar to the passive management by exception and laissez-faire dimensions of the MLQ, we believe that they are also most different from the contingent reward and contingent punishment dimensions of the LRPQ developed by Podsakoff and Skov and presented in full in Podsakoff et al. (1984, p. 38). The LRPQ consists of four subscales. Contingent reward is the leader's positive response to desired performance, which is similar to the MLQ construct of the same name. Contingent punishment is the leader's performance-related response to undesired behavior; it appears to be most similar to the active management by exception construct of the MLQ. Noncontingent reward and punishment have no parallel constructs in the MLQ and refer to positive (rewarding) and negative (punishing) leader behaviors that are unrelated to performance. The LRPQ has demonstrated an excellent factor structure and acceptable levels of internal consistency reliability in previous research (see Podsakoff et al., 1982, 1984, 2006), although the two negatively worded items of the contingent reward measure have been problematic. (As the focus of Study 2 was on performance-related leader behavior, LRPQ noncontingent reward and noncontingent punishment were not included in our analyses.)

Ignoring the traditional reinforcement approach (e.g., Rachlin, 1989; Skinner 1969), we could advance a somewhat cynical argument that reward omission is simply the absence of contingent reward and that punishment omission is merely the absence of contingent punishment. If this were the case, we would expect the contingent reward and reward omission items to load on a single factor in a factor analysis (with the contingent reward or reward omission items having negative loadings) and the contingent punishment and punishment omission items to load similarly on another factor. Consequently, to provide additional supportive evidence concerning the construct validity of our new measures, we wanted to see if they were perceived by survey respondents as independent constructs or as negatively worded contingent reward and punishment items. Thus, we undertook a second study that employed LISREL maximum likelihood confirmatory factor analysis (Joreskog \& Sorbom, 2002) to assess the goodness of fit of two hierarchically nested rival models to the data (seeWidaman, 1985): a two-factor model and a four-factor model.

\section{Samples and Procedures}

We conducted this analysis with three independent samples to increase confidence in our results. Sample 1 consisted of 297 midlevel managers employed at over 100 U.S. financial institutions. The average age of the respondents was 32 years, and $69 \%$ were male. The average professional tenure of the respondents was 4.3 years, and they had worked with their current supervisors for an average of 10 months. Over $90 \%$ of the respondents were college graduates, and all had at least some college education. The researchers administered survey questionnaires to the bankers at the beginning of a 2-week, industrysponsored management effectiveness program held at a large eastern U.S. university. Brief oral presentations were made to explain the purpose of the research, and the bankers were given the opportunity to ask questions. They were encouraged to answer all questions honestly. Participation was voluntary, and the sample was assured of complete anonymity.

Sample 2 consisted of 241 administrative and supervisory employees who worked for two U.S. hotel companies at various locations around the country. The average age of the respondents was 38 years, and $53 \%$ were male. Surveys were administered at the properties and were returned directly to the researchers following completion. There were 42 referent managers for an average of 5.6 respondents per manager. Also included in the survey were the MLQ transactional leadership and laissez-faire scales, as well as measures of satisfaction with supervisor, supervisor effectiveness, and role clarity that are described below. Respondents were encouraged to answer all questions honestly. Participation was voluntary, and the 
sample was assured of complete anonymity.

Sample 3 consisted of 261 full-time employees at all hierarchical levels of a large commercial bakery; they worked for a total of 38 different supervisors (average of 6.9 respondents per supervisor). The researchers administered the employee surveys on site, during the normal workday, and in small groups (away from the supervisors). Written instructions, as well as verbal instructions and assurances, were provided (along with a brief and general summary of the study's purpose). The employees were requested to identify themselves by providing the last three digits of their employee numbers and university sponsorship, and the confidentiality of their answers was emphasized. Slightly less than half of those surveyed had at least a 2-year college or technical degree (43.1\%), and $87.2 \%$ had completed high school. The average age of the respondents was 37.5 years, and $61 \%$ of respondents were male.

\section{Methods of Analysis}

The first confirmatory model was a two-factor model; it was specified that the contingent reward and reward omission items loaded on the same factor and that the contingent punishment and punishment omission items loaded on the second factor. The second model was a four-factor model; it was specified that the items of each scale loaded on only the appropriate factor. This model assumes that reward and punishment omission are independent constructs that are separate and distinct from contingent reward and punishment. The measures included the four-item reward and punishment omission scales retained from

Study 1. To maintain equality in the number of items representing each construct, we conducted an exploratory factor analysis of the LRPQ with the first sample and retained the four highest loading contingent reward and punishment items for our subsequent sets of analyses. Respondents were asked to indicate the extent to which their managers exhibited the leadership behaviors using a 7-point Likert scale (from strongly disagree to strongly agree). Following recommended practice (see Joreskog \& Sorbom, 2002; Widaman, 1985), we based the analyses on item covariances and employed common factor models with correlated factors and uncorrelated error.

\section{Results}

All of the items had statistically significant factor loadings $(p<.01)$ in both the two- and four-factor models in all three samples. The two-factor models revealed that the contingent reward and contingent punishment items had significant negative loadings and that the reward omission and punishment omission items had significant positive loadings. As expected, however, the chi-square results in all three samples clearly indicated that the four-factor model was a significantly better fit to the data (Sample $1, \Delta y^{2}(5)=$ 63.98, $p<.001$; Sample 2, $\Delta x^{2}(5)=95.89, p<.001$; Sample 3, $\left.\Delta x^{2}(5)=165.79, p<.001\right)$. The goodness-of-fit results are presented in Table 3. As shown in Table 3, all of the four-factor fit indices were in the acceptable range for model fit (Hu \& Bentler, 1999), and all were better than were the indices for the two-factor models. These results support the idea that, even though these four dimensions deal with a leader's response to good (reward omission and contingent reinforcement) and poor (punishment omission and contingent punishment) subordinate performance, the reward and punishment omission constructs are empirically (perceptually) separate and distinct. This, of course, is in addition to their being theoretically distinct from similar constructs (passive management by exception and laissez-faire leadership), as shown in Study 1. 


\section{Study 3: A Test of New Scale Convergent, Discriminant, Concurrent, and Incremental Concurrent Validity}

\section{Hypotheses}

To provide additional support for the validity of the new omission constructs, we decided to examine their relationships with measures of similar and dissimilar constructs and their concurrent correlations with relevant dependent variables. For these purposes, the MLQ-5X (Bass \& Avolio, 1993, 1997) was administered to Sample 2 (described above), along with the omission scales and three outcome measures. Of particular relevance in the current study are the four nontransformational behaviors that include contingent reward, active management by exception, passive management by exception, and laissez-faire leadership.

As discussed earlier, passive management by exception is similar to the new omission constructs in that it involves inaction (as long as things seem to be going all right). Similarly, laissez-faire leadership is characterized as generally ignoring problems and subordinate needs. Because these two dimensions are at least superficially similar to the omission constructs, they should be somewhat related to both. On the other hand, because active management by exception involves looking for subordinate mistakes and taking action if targets are not met, it would be expected to have either a substantially weaker or no relationship with both types of omission. Contingent reward behavior, characterized by the active administration of desirable outcomes contingent upon subordinate performance, should be inversely related to both types of nonaction

Table 3

Confirmatory Factor Analysis Results

\begin{tabular}{|c|c|c|c|c|c|c|}
\hline Variable & Two-factor model & Four-factor model & Two-factor model & Four-factor model & Two-factor model & Four-factor model \\
\hline$\chi^{2}$ & 365.69 & 301.71 & 275.02 & 179.13 & 368.89 & 203.10 \\
\hline RMSEA & .09 & .08 & .09 & .07 & .10 & .06 \\
\hline CFI & .95 & .97 & .93 & .97 & .83 & .93 \\
\hline
\end{tabular}

Note. $\quad$ RMSEA $=$ root-mean-square error of approximation; CFI $=$ comparative fit index; NFI $=$ normed fit index.

(omission), because leaders who are seen as active are not likely also to be seen as inactive. Furthermore, contingent reward behavior should be more strongly and negatively related to reward omission than to punishment omission, as the same leader behavior is highly unlikely to be perceived as simultaneously rewarding and not rewarding subordinate performance. These expectations led to the following convergent and discriminant validity hypotheses.

Hypothesis 1: Perceived passive management by exception will be positively related to perceived leader reward omission (1A) and punishment omission (1B); perceived laissez-faire leadership will be positively related to perceived leader reward omission (1C) and punishment omission (1D).

Hypothesis 2: The relationship between perceived leader reward omission and active management by exception will be less than the relationship between reward omission and passive management by exception (2A); the relationship between perceived leader reward omission and active management by exception will be less than the relationship between reward omission and laissezfaire leadership (2B); the relationship between perceived leader punishment omission and active 
management by exception will be less than the relationship between punishment omission and passive management by exception (2C); the relationship between perceived leader punishment omission and active management by exception will be less than the relationship between punishment omission and laissez-faire leadership (2D).

Hypothesis 3: Perceived leader contingent reward behavior will be negatively related to perceived reward omission ( $3 \mathrm{~A}$ ) and punishment omission behavior (3B); the relationship will be stronger with reward omission than with punishment omission (3C).

With respect to dependent variables and concurrent validity, studies that used the MLQ have been focused on transformational leadership. Much less attention has been paid to the other nontransformational behaviors (except for contingent reward) and their relationships with dependent variables. Satisfaction with supervision and perceived supervisor effectiveness have been the dependent variables most commonly used in studies of transactional leadership (Dumdum et al., 2002), although perceived role clarity has been frequently used in studies of contingent reward as measured by the LRPQ (Podsakoff et al., 2006). Recent metaanalyses summarizing the findings of all available studies of transactional leadership have found that passive management by exception has negative relationships and that active management by exception has weak positive correlations with the satisfaction and effectiveness variables. Contingent reward demonstrated strong positive relationships with both variables and with role clarity, whereas laissezfaire leadership had strong negative relationships with the satisfaction and effectiveness variables (Judge \& Piccolo, 2004; Podsakoff et al., 2006). Reward omission would be expected to have strong negative relationships with perceptions of supervisor effectiveness and satisfaction with the supervisor, but the effects of punishment omission are less clear. Bass et al. (2003) discussed the important role that contingent reward and active management by exception have on clarifying follower expectations. A recent study found laissez-faire leadership to be strongly related to role ambiguity and role conflict (Skogstad et al., 2007). On the basis of our earlier discussion, we expected that both types of omission would have negative relationships with role clarity.

Hypothesis 4: Perceived leader reward omission behavior will have negative relationships with perceptions of supervisor effectiveness (4A), satisfaction with supervision (4B), and role clarity (4C).

Hypothesis 5: Perceived leader punishment omission behavior will have a negative relationship with subordinate- perceived role clarity.

Because the new leader omission scales tap an important aspect of leadership that we believe is not currently being directly measured by existing scales, we thought it desirable to test their incremental usefulness for the study of leadership phenomena. Bass et al. (2003) discussed the use of hierarchical regression to test for the augmentation effect of transformational leadership on contingent reward behavior in predicting performance. Employing their methodology, we used regression to determine if the omission constructs made a unique incremental contribution to explaining variance in the three dependent variables we discuss above (role clarity, satisfaction with supervision, and supervisory effectiveness). To test their empirical usefulness, we therefore proposed three final hypotheses for Study 3 concerning scale incremental concurrent validity.

Hypothesis 6: Reward omission will be significantly related to perceived supervisor effectiveness after controlling for the effects of contingent reward, active and passive management by exception, and laissez-faire leadership. 
Hypothesis 7: Reward omission will be significantly related to satisfaction with supervision after controlling for the effects of contingent reward, active and passive management by exception, and laissez-faire leadership.

Hypothesis 8: Reward omission (8A) and punishment omission (8B) will be significantly related to subordinate perceptions of role clarity after controlling for the effects of contingent reward, active and passive management by exception, and laissez-faire leadership.

\section{Sample and Measures}

The sample consisted of the 241 hotel employees in Sample 2 (described above). The measures included the four-item Reward Omission and Punishment Omission scales shown in the Appendix and the three transactional and laissez-faire leadership dimensions of the MLQ-5X (Bass \& Avolio, 1993). These measures employed a 5-point Likert response scale (from not at all to frequently, if not always). Satisfaction with the supervisor was measured with the Supervisor-Human Relations and the Supervisor-Technical Ability subscales ( 5 items apiece) of the Minnesota Satisfaction Questionnaire (MSQ; Weiss, Dawis, England, \& Lofquist, 1967). We used this measure because it assesses satisfaction with the supervisor rather than global satisfaction. The 10 items were assessed on a 5-point Likert scale (from very dissatisfied to very satisfied) and were combined to create an overall satisfaction with supervision measure. Supervisor effectiveness was measured on six dimensions: technical competence, interpersonal skill, procedural justice, organizational influence, communication, and goal clarification. Respondents were asked to rate each of these dimensions on a 7-point scale (from highly ineffective to highly effective). The 6 items were then aggregated to create a total effectiveness measure. The role clarity measure we employed (Rizzo et al., 1970) consists of 6 items and measures the extent to which individuals clearly understand their task and role in the employing organization.

\section{Methods of Analysis}

Correlation and reliability. To test Hypotheses 1 through 5, we computed Pearson correlations among all the variables to enable the examination of relationships among the leader behaviors and dependent variables. Coefficient alpha internal consistency reliabilities were computed for the measures; all of the scales had reliabilities that were in excess of .70 and were therefore acceptable (Nunnally \& Bernstein, 1994).

Multiple regression analysis. To examine incremental concurrent validity (Hypotheses 6-8), we based our analyses on Bass et al. (2003) and conducted three hierarchical regression analyses. These analyses included all six leader behavior scales as independent variables and employed perceived supervisor effectiveness, satisfaction with supervision, and role clarity as the dependent variables. Following Bass et al. (2003), we entered all four MLQ measures and then added reward and punishment omission to the equation in the second and final step.

Common method variance and higher order factor analyses. Finally, there is always the possibility of artifacts with all selfreport surveys. We therefore conducted two supplemental analyses. The first was a higher order confirmatory factor analysis, to determine if the six leadership measures could be conceptualized as being merely facets of a more global perception of good or poor leadership. The second supplemental analysis assessed the degree to which our obtained correlation and regression results might be attributable to the effects of common method variance. These analyses followed the procedures 
described and recommended by Podsakoff, MacKenzie, Lee, and Podsakoff (2003) and Williams, Ford, and Nguyen (2002). To test for the higher order factor, we introduced a seventh factor to our model that comprised the six latent leadership variables. The common method model involved adding another factor that comprised the indicator variables from the six leadership measures and the three dependent variables. Covariance matrices were the data for these analyses, and the models specified correlated factors and uncorrelated error; the method factor was specified as uncorrelated with the nine leadership and dependent variable constructs, as is recommended and common practice (Podsakoff et al., 2003; Williams et al., 2002).

\section{Results}

Correlations. Looking first at the dependent variable correlations shown in Table 4, contingent reward showed a strong positive relationship with supervisor effectiveness, supervisor satisfaction, and role clarity, and passive management by exception and laissez-faire showed strong negative relationships. Active management by exception had a significant but weak negative relationship with supervisor effectiveness and supervisor satisfaction and a nonsignificant relationship with role clarity. These findings are very consistent with those of prior research on contingent reward and laissez-faire leadership, but the relationships between the dependent variables and both forms of management by exception are generally stronger than those previously reported (e.g., Dumdum et al., 2002; Judge and Piccolo, 2004; Lowe et al., 1996). Reward omission had strong negative relationships and punishment omission had moderately strong negative relationships with the dependent variables. Looking at the relationship between the omission measures and the MLQ measures, a strong negative relationship between reward omission and contingent reward was apparent (as expected). Reward omission also had a strong positive relationship with passive management by exception and laissez- faire, and punishment omission had a moderately strong relationship with passive management by exception and laissez-faire. Overall, these relationships confirm Hypotheses 1 through 5 and therefore provide support for the construct validity of the omission measures in terms of convergent, discriminant, and concurrent validity. In the top part of Table 6, we summarize the first five hypotheses, report the test results pertinent to each, and indicate that each of the five hypotheses was fully supported by the data.

Regressions. As shown in Table 5, for the supervisor effectiveness dependent variable, passive management by exception,

Table 4

Study 3 (Sample 2) Scale Intercorrelations and Internal Consistency Reliabilities

\begin{tabular}{|c|c|c|c|c|c|c|c|c|c|c|c|}
\hline Variable & $M$ & $S D$ & 1 & 2 & 3 & 4 & 5 & 6 & 7 & 8 & 9 \\
\hline 1. Contingent reward & 2.34 & 0.91 & .88 & & & & & & & & \\
\hline 2. Active management by exception & 2.78 & 0.70 & .01 & .72 & & & & & & & \\
\hline 3. Passive management by exception & 2.17 & 0.91 & $-.28^{* *}$ & $.22^{* *}$ & .85 & & & & & & \\
\hline 4. Laissez-faire & 1.87 & 0.72 & $-.28^{* *}$ & $.15^{*}$ & $.78^{* *}$ & .80 & & & & & \\
\hline 5. Reward omission & 3.71 & 1.83 & $-.46^{* *}$ & $.22^{* *}$ & $.50^{* *}$ & $.49^{* *}$ & .90 & & & & \\
\hline 6. Punishment omission & 2.50 & 1.37 & $-.17^{*}$ & $-.20^{* *}$ & $.36^{* *}$ & $.39^{* *}$ & $.37^{* *}$ & .82 & & & \\
\hline 7. Supervisor effectiveness & 5.17 & 1.30 & $.58^{* *}$ & $-.17^{*}$ & $-.62^{* *}$ & $-.61^{* *}$ & $-.63^{* *}$ & $-.34^{* *}$ & .89 & & \\
\hline 8. Supervisor satisfaction & 3.55 & 1.02 & $.52^{* *}$ & $-.18^{* *}$ & $-.59^{* *}$ & $-.58^{* *}$ & $-.63^{* *}$ & $-.37^{* *}$ & $.75^{* *}$ & .91 & \\
\hline 9. Role clarity & 5.45 & 1.10 & $.39^{* *}$ & -.09 & $-.40^{* *}$ & $-.47^{* *}$ & $-.40^{* *}$ & $-.32^{* *}$ & $.60^{* *}$ & $.57^{* *}$ & .86 \\
\hline
\end{tabular}

Note. $\quad N=241$. Cronbach's alphas are shown on the main diagonal.

${ }^{*} p<.05 . \quad{ }^{*} p<.01$. 
Study 3 (Sample 2) Significant Hierarchical Regression Analysis Results

\begin{tabular}{|c|c|c|c|c|c|}
\hline \multirow[b]{2}{*}{ Step and variable entered } & \multicolumn{2}{|c|}{$\begin{array}{l}\text { Unstandardized } \\
\text { coefficients }\end{array}$} & \multirow{2}{*}{$\begin{array}{c}\begin{array}{c}\text { Standardized } \\
\text { coefficient }\end{array} \\
\beta\end{array}$} & \multirow[b]{2}{*}{$t$} & \multirow[b]{2}{*}{$p$} \\
\hline & $B$ & $S E$ & & & \\
\hline \multicolumn{6}{|c|}{ Dependent variable: Supervisor effectiveness ${ }^{a}$} \\
\hline 1. Constant & 6.39 & .30 & & 21.33 & .01 \\
\hline 1. Passive management by exception & -0.31 & .10 & -.22 & -3.25 & .01 \\
\hline 1. Laissez-faire & -0.44 & .13 & -.24 & -3.52 & .01 \\
\hline 1. Contingent reward & 0.40 & .07 & .29 & 5.69 & .01 \\
\hline 2. Reward omission & -0.18 & .04 & -.26 & -4.75 & .01 \\
\hline \multicolumn{6}{|c|}{ Dependent variable: Satisfaction with supervisor ${ }^{\mathrm{b}}$} \\
\hline 1. Constant & 4.74 & .25 & & 18.83 & .01 \\
\hline 1. Passive management by exception & -0.20 & .08 & -.18 & -2.44 & .05 \\
\hline 1. Laissez-faire & -0.38 & .11 & -.26 & -3.58 & .01 \\
\hline 1. Contingent reward & 0.25 & .06 & .22 & 4.18 & .01 \\
\hline 2. Reward omission & -0.17 & .03 & -.31 & -5.49 & .01 \\
\hline \multicolumn{6}{|l|}{ Dependent variable: Role clarity ${ }^{\mathrm{c}}$} \\
\hline 1. Constant & 6.04 & .32 & & 18.92 & .01 \\
\hline 1. Laissez-faire & -0.51 & .11 & -.32 & -4.71 & .01 \\
\hline 1. Contingent reward & 0.29 & .08 & .23 & 3.72 & .01 \\
\hline 2. Punishment omission & -0.13 & .05 & -.16 & -2.45 & .05 \\
\hline
\end{tabular}

Note. $\quad N=241$. Only significant variables are shown.

${ }^{\text {a }}$ Adjusted $R^{2}=.62$. ${ }^{\mathrm{b}}$ Adjusted $R^{2}=.56 .{ }^{\mathrm{c}}$ Adjusted $R^{2}=.30$.

laissez-faire, contingent reward, and reward omission were all significant "predictors." For supervisor effectiveness, the addition of reward omission in Step 2 increased the adjusted $R^{2}$ from .57 to .62. For supervisor satisfaction, the same variables were again significant, and the adjusted $\mathrm{R}^{2}$ increased in Step 2 from .49 to .56 . For role clarity, only laissez-faire, contingent reward, and punishment omission were significant; and the adjusted $\mathrm{R}^{2}$ increased from .28 to .30 with the inclusion of punishment omission in Step 2.

As we summarize in the bottom half of Table 6, these results fully support Hypotheses 6 and 7 and partially support Hypothesis 8 . In general, the omission measures did serve to augment the effects of the four MLQ transactional leadership measures. The omission measures provided empirical evidence that supports the incremental concurrent validity of these constructs, as well as the potential importance of omission for inclusion in future leadership research.

Supplemental analyses. The results from our first set of supplemental analyses revealed that the confirmatory common factor model with six first-order leadership factors was a significantly better fit to the data than was the model with six first-order leadership factors and a second-order general leadership factor, $\Delta x^{2}(9)=166.58, p<.001$. Thus, the data do not appear to support the possibility that the respondents were simply reporting their conceptions of good or poor leadership using the six leadership measures that they completed.

The common method variance analyses showed that adding a method factor to the nine substantive construct factors (six leadership and three dependent variables) did improve model fit, $\Delta x^{2}(61)=663.84, p<$ 
.001; comparative fit indices, normed fit indices, and root-mean-square errors of approximation improved from .92 , .89, and .09 to $.94, .91$, and .07 , respectively. Computing the incremental explained variance in the model by squaring the standardized factor loadings revealed that the common method factor increased explained variance by an average of $24 \%$ per item. Further examination of the item factor loadings revealed that 58 of the 61 item loadings remained significant on their appropriate factor (one passive management by exception item, one contingent reward item, and one supervisor effectiveness item were the exceptions). The latent variable correlations were generally reduced by inclusion of the common method factor (see Table 7), but all of the relationships examined remained statistically significant, as shown in the lower portion of Table 7. Additionally, only the findings shown in Table 6 with respect to Hypotheses 2B and 2D were contradicted when we used the latent variable correlations with estimated common method variance. This result is partly explainable by the fact that latent variable correlations are corrected for measurement error. The Active Management by Exception Scale had a lower estimated scale reliability (.72) than did the Passive Management by Exception and Laissez-Faire Leadership Scales (.85 and .80, respectively).

\section{Study 4: A Further Test of New Scale Validity}

Study 3 generally supported the convergent, discriminant, concurrent, and incremental concurrent validity of the new reward omission and punishment omission measures, and this remained true even after we controlled for common method variance artifacts. Although these results are encouraging, one important concern that remains unaddressed is whether the new measures have any systematic relationship with variables that are measured via a different data source. In particular, subordinate performance would seem an especially relevant variable for such an examination, because omission involves a leader's response to prior subordinate performance-which may then impact on the subordinate's future job behavior.

We therefore undertook Study 4 to examine relationships between subordinate-provided descriptions of their supervisor's omission behavior at one time and supervisor-provided ratings of subordinate performance approximately 3 months later. Additionally, as we were able to collect subordinate descriptions of leader contingent reward and punishment behavior and satisfaction with supervision, we decided to further test the convergent, discriminant, and concurrent validity of the new omission scales.

According to the reinforcement paradigm, behavior can be maintained or increased by contingent rewards and reduced or eliminated by contingent punishment (Luthans \& Kreitner, 1985; Skinner, 1969). Because reward omission refers to leader behavior that does not reinforce good performance, it seems reasonable to expect that the omission of rewards for good performance should lead to reduced subsequent subordinate performance (i.e., leader reward omission should be negatively related to future subordinate job performance). Correspondingly, because punishment omission involves the supervisor failing to punish or stop poor performance, the subsequent performance of the subordinate should remain unaltered (i.e., leader punishment omission should be unrelated to future subordinate job performance). Because this latter expectation cannot be scientifically formulated (one cannot test a null hypothesis; McNemar, 1969), we made the following hypothesis:

Hypothesis 9: Perceived leader reward omission behavior will be negatively related to subsequent subordinate job performance.

Finally, because we collected data that permitted us to retest Hypotheses 3A, 3B, 3C and Hypothesis 4B from Study 3 (see Table 6), we report these results below. 
Table 6

Summary of Study 3 Hypotheses, Results, and Inferences Drawn (Using Sample 2)

\begin{tabular}{|c|c|c|c|}
\hline Hypothesis $^{\mathrm{a}}$ & Statistical test ${ }^{\mathrm{b}}$ & Results $^{\mathrm{c}}$ & Inference \\
\hline $1 \mathrm{~A}$ & $r_{\text {RO.MBEP }}>.0$ & $r_{\text {RO.MBEP }}=.50^{* *}$ & Supported \\
\hline 1B & $r_{\text {PO.MBEP }}>.0$ & $r_{\mathrm{PO} . \mathrm{MBEP}}=.36^{* *}$ & Supported \\
\hline $1 \mathrm{C}$ & $r_{\text {RO.LF }}>.0$ & $r_{\mathrm{RO} . \mathrm{LF}}=.49^{* *}$ & Supported \\
\hline 1D & $r_{\text {PO.LF }}>.0$ & $r_{\mathrm{PO} . \mathrm{F}}=.39^{* *}$ & Supported \\
\hline $2 \mathrm{~A}$ & $r_{\text {RO.MBEA }}<r_{\text {RO.MBEP }}$ & $t=-4.03^{* *}$ & Supported \\
\hline $2 \mathrm{~B}$ & $r_{\text {RO.MBEA }}<r_{\text {RO.LF }}$ & $t=-3.72^{* *}$ & Supported \\
\hline $2 \mathrm{C}$ & $r_{\text {PO.MBEA }}<r_{\text {PO.MBEP }}$ & $t=-7.70^{* *}$ & Supported \\
\hline $2 \mathrm{D}$ & $r_{\text {PO.MBEA }}<r_{\text {PO.LF }}$ & $t=-7.91^{* *}$ & Supported \\
\hline $3 \mathrm{~A}$ & $r_{\mathrm{RO} . \mathrm{CR}}<.0$ & $r_{\mathrm{RO} . \mathrm{CR}}=-.46^{* *}$ & Supported \\
\hline 3B & $r_{\text {PO.CR }}<.0$ & $r_{\mathrm{PO} . \mathrm{CR}}=-.17^{*}$ & Supported \\
\hline $3 \mathrm{C}$ & $r_{\mathrm{RO} . \mathrm{CR}}<r_{\mathrm{PO} . \mathrm{CR}}$ & $t=-4.49^{* *}$ & Supported \\
\hline $4 \mathrm{~A}$ & $r_{\text {RO.Effectiveness }}<.0$ & $r_{\text {Ro.Effectiveness }}=-.63^{* *}$ & Supported \\
\hline 4B & $r_{\text {RO.Satisfaction }}<.0$ & $r_{\text {RO.Satisfaction }}=-.63^{* *}$ & Supported \\
\hline $4 \mathrm{C}$ & $r_{\text {RO.Role Clarity }}<.0$ & $r_{\text {RO.Role Clarity }}=-.40^{* *}$ & Supported \\
\hline 5 & $r_{\text {PO.Role Clarity }}<.0$ & $r_{\text {PO.Role Clarity }}=-.32^{* *}$ & Supported \\
\hline 6 & $B_{\text {RO.Effectiveness }} \neq .0$ & $B_{\text {RO.Effectiveness }}=-.26^{* *}$ & Supported \\
\hline 7 & $B_{\text {Ro.Satisfaction }} \neq .0$ & $B_{\text {RO.Satisfaction }}=-.31^{* *}$ & Supported \\
\hline $8 \mathrm{~A}$ & $B_{\text {Ro.Role Clarity }} \neq .0$ & $B_{\text {Ro.Role Clarity }}=n s$ & Not supported \\
\hline $8 B$ & $B_{\text {PO.Role Clarity }} \neq .0$ & $B_{\text {PO.Role Clarity }}=-.16^{*}$ & Supported \\
\hline
\end{tabular}

Note. $\quad \mathrm{RO}=$ reward omission; $\mathrm{MBEP}=$ management by exception-passive $; \mathrm{PO}=$ punishment omission; $\mathrm{LF}=$ laissez-faire; MBEA = management by exception-active; $\mathrm{CR}=$ contingent reward; effectiveness = supervisor effectiveness; satisfaction = supervisor satisfaction.

${ }^{a}$ The hypotheses are numbered and lettered as presented in the text.

${ }^{\mathrm{b}}$ Correlations between two variables $\left(r_{\mathrm{X} . \mathrm{Y}}\right)$ have a dot separating the variable symbols. The symbol $\neq$ denotes "not equal to." The symbol $B_{X . Y}$ denotes the standardized regression coefficient obtained by regressing independent variable $X$ on dependent variable $Y$, after entering the MBEA, MBEP, LF, and CR variables.

${ }^{\mathrm{c}} T$-test results shown are from the test for differences between correlations in correlated samples (given in McNemar, 1969, p. 158).

${ }^{*} p<.05 .{ }^{* *} p<.01$.

Table 7

Study 3 (Sample 2) Estimated Latent Variable Intercorrelation (Phi) Matrices With and Without a Common Method

\begin{tabular}{lccccccccc}
\hline \multicolumn{1}{c}{ Variable } & 1 & 2 & 3 & 4 & 5 & 6 & 7 & 8 \\
\hline 1. Reward omission & - & $0.44^{* *}$ & $-0.48^{* *}$ & $-0.64^{* *}$ & $-0.75^{* *}$ & $0.65^{* *}$ & $0.32^{* *}$ & $0.57^{* *}$ & $-0.71^{* *}$ \\
2. Punishment omission & $0.37^{* *}$ & - & $-0.53^{* *}$ & $-0.43^{* *}$ & $-0.40^{* *}$ & $0.49^{* *}$ & $-0.21^{* *}$ & $0.36^{* *}$ & $-0.31^{* *}$ \\
3. Role clarity & $-0.15^{*}$ & $-0.46^{* *}$ & - & $0.68^{* *}$ & $0.67^{* *}$ & $-0.64^{* *}$ & $-0.21^{* *}$ & $-0.52^{* *}$ & $0.49^{* *}$ \\
4. Supervisor satisfaction & $-0.14^{* *}$ & $-0.37^{* *}$ & $0.51^{* *}$ & - & $0.87^{* *}$ & $-0.79^{* *}$ & $-0.37^{* *}$ & $-0.68^{* *}$ & $0.75^{* *}$ \\
5. Supervisor effectiveness & $-0.32^{* *}$ & $-0.42^{* *}$ & $0.55^{* *}$ & $0.62^{* *}$ & - & $-0.77^{* *}$ & $-0.38^{* *}$ & $-0.69^{* *}$ & $0.76^{* *}$ \\
6. Laissez-faire & $0.39^{* *}$ & $0.41^{* *}$ & $-0.46^{*}$ & $-0.62^{* *}$ & $-0.66^{* *}$ & - & $0.31^{* *}$ & $0.89^{* *}$ & $-0.60^{* *}$ \\
7. Active management by exception & $0.26^{* *}$ & $0.50^{* *}$ & $-0.18^{* *}$ & $-0.28^{*}$ & $-0.51^{* *}$ & $0.17^{* *}$ & - & $0.34^{* *}$ & $-0.15^{* *}$ \\
8. Passive management by exception & $0.30^{* *}$ & $0.26^{* *}$ & $-0.32^{* *}$ & $-0.47^{*}$ & $-0.53^{* *}$ & $-0.82^{* *}$ & 0.08 & $-0.55^{* *}$ \\
9. Contingent reward & $-0.32^{* *}$ & $-0.13^{*}$ & $0.24^{* *}$ & $0.45^{*}$ & $0.45^{* *}$ & $-0.32^{* *}$ & $-0.47^{* *}$ & $-0.29^{* *}$ & - \\
10. Common method factor & - & - & - & - & - & - & - & - & - \\
\hline
\end{tabular}

Note. $\quad N=241$. The phi matrix without the common method factor is presented above the main diagonal; the phi matrix with the common method factor is presented below the main diagonal.

${ }^{*} p<.05 .{ }^{* *} p<.01$.

\section{Sample, Procedure, and Measures}

Sample. The sample consisted of the 261 full-time bakery employees in Sample 3 (for a description, see Study 2). 
Procedure. We employed the procedure as that in Study 2 to administer the employee survey and collect the employee data. Additionally, 14 weeks after the employees had completed their surveys on site, we asked the 38 supervisors of these respondents to complete short performance appraisals for each of their subordinates who had completed an employee survey. The supervisors used a master list supplied by the company's human resources department to identify each employee by the last three digits of his or her employee number. In conformity with our briefings of the employees and supervisors (and our informed consent protocols), we deleted the employee numbers and all personal identification from our records and the data after the employee and supervisor data had been collated.

Measures. The reward and punishment omission measures were identical to those employed earlier and are shown in the Appendix. The Leader Contingent Reward and Leader Contingent Punishment scales were identical to those employed earlier; they were the four best items of each LRPQ scale (Podsakoff et al., 1982, 1984, 2006), as identified in Sample 1 (see Study 2). We had the opportunity to measure employee satisfaction with supervisors and employed the 10 items from the Minnesota Satisfaction Questionnaire (Weiss et al., 1967) used with Sample 2 in Study 3.

The Performance Rating scale administered to the supervisors was a 7-item measure that was based on a scale originally developed by Mott (1972). Previous research using this measure (e.g., Schriesheim, Neider, \& Scandura, 1998) suggests that it has good reliability and significant correlations with other performance indicators (such as units produced as a percentage of standard). Two sample items are "Productivity-Quantity: Thinking of the various things which this person does for his/her job, how much is he/she producing (e.g., units produced, customers served, forms completed, pallets loaded, etc.)?" and "Production-Quality: How good would you say is the quality of the performance of this person? Check one." The additional dimensions measured were "Production-Efficiency," "Anticipating Problems and Solving Them Satisfactorily," "Awareness of Potential New Solutions," "Promptness of Adjustment," and "FlexibilityCoping With Emergencies." At the company's insistence, the response categories for these items were 1 (Below Average), 2 (Average or About Average), and 3 (Above Average).

\section{Methods of Analysis}

To test Hypotheses 3A, 3B, and 3C and Hypotheses 4B and 9, we computed Pearson correlations among the six variables to enable the examination of relationships among the four leader behaviors and two dependent variables. We computed coefficient alpha internal consistency reliabilities for the measures. All reliabilities exceeded .70 and were therefore acceptable (Nunnally \& Bernstein, 1994).

\section{Results}

When we look at the computed correlations shown in Table 8, Hypotheses 3A, 3B, and 3C and Hypotheses 4B and 9 all appear to be supported. This result essentially replicates the results of Study 3 . First and most important, perceived leader reward omission was negatively and significantly related to subsequent subordinate performance ( $r=-.20, p<.01$; Hypothesis 9$)$. Additionally, as expected but not hypothesized, the performance correlation for punishment omission was trivial and nonsignificant $(r=.04)$. Finally, contingent reward had a moderately strong positive relationship with subsequent performance, as would be expected $(r=.31, p<.01)$.

Hypothesis $3 \mathrm{~A}$ predicted that the correlation between reward omission and contingent reward would be negative and significant, and Hypothesis 3B predicted a negative and significant correlation 
between punishment omission and contingent reward. As shown in Table 8, both of these predictions were supported ( $r$ of -.70 and -.19 , respectively; both ps < .01). Additionally, Hypothesis $3 C$ predicted that the correlation between reward omission and contingent reward would be stronger than would the correlation between punishment omission and contingent reward. Again, this hypothesis was supported, $\mathrm{t}(257)=-$ $5.30, p<.01$. Finally, Hypothesis 4B predicted a significant and negative correlation between reward omission and satisfaction with supervision. The results shown in Table 8 clearly support this expectation $(r=$ $-.53, p<.01)$.

\section{General Discussion}

Our primary goals in this research were to examine inactive or nonresponsive leadership in more depth; to refine and extend the idea of a leadership reinforcement continuum proposed by Judge and Piccolo (2004); and to develop new scales (and provide preliminary evidence of their validity and utility) to measure more specific and focused nonreactive leader behavior from a reinforcement perspective, so the positive and negative effects of such behavior could be studied more rigorously in the future.

The content adequacy assessment demonstrated that leader reward and punishment omission are theoretically separate and distinct from each other and similar or related constructs (in particular, laissezfaire leadership and passive management by exception). Also, the confirmatory factor analyses with three independent samples yielded additional evidence that supported the empirical (perceptual) distinctiveness of these two new constructs and thereby further supported their construct validity.

We found additional support for the construct validity of the new omission scales. They were related (largely as predicted) to MLQ and LRPQ transactional and laissez-faire leadership, satisfaction with supervision, subordinate-perceived supervisor effectiveness, role clarity, and subsequent supervisor-rated employee performance. Also, the new omission scales demonstrated good internal consistency reliabilities.

The consistency of our correlational results for the MLQ and LRPQ subscales with prior research involving satisfaction, effectiveness, and role clarity (Judge \& Piccolo, 2004; Podsakoff et al., 2006) allows us to interpret the obtained results with the omission measures as probably being generalizable and not sample specific. Additionally, the fact that omission augmented the effects of transactional and laissez-faire leadership scales in Study 3 suggests not only that these behaviors are theoretically and empirically different from other leadership behaviors but that they may have important independent effects on subordinate outcome variables.

Prior studies have shown that considerable variance exists in the type and amount of reinforcement provided to subordinates by managers. We found it possible to make predictions about relationships between omission and the outcome variables on the basis of theories of reinforcement, attribution, equity, and organizational justice and the results from earlier studies that used the MLQ and LRPQ. Omission was generally negatively related to satisfaction with supervision, negatively related to role clarity, and either negatively related or unrelated to supervisor effectiveness. These relationships suggest that not responding to poor performance may very well have negative effects on perceptions of supervisors by subordinates and, quite possibly, on subordinates' subsequent performance. In essence, the current study demonstrates that subordinates in work organizations may be as sensitive to the reinforcement that they do not receive (but may want or feel that they deserve) as they are to the rewards and punishments that they do receive.

In agreement with other scholars (e.g., Klein, Dansereau, \& Hall, 1994), we have previously argued 
that level of analysis should routinely be examined in leadership research (e.g., Schriesheim, Castro, Zhou, \& Yammarino, 2001). Unfortunately, however, our agreements with the sponsoring organizations of Samples 1,2 , and 3 did not permit us to code or analyze the data in such a way as to allow us to use data analytic techniques (such as within- and between-entities analysis; Dansereau, Alutto, \& Yammarino, 1984) to examine relationships at the dyad, individual-within-groups, or across-group levels. Our analyses are thus based strictly on methods that assume all effects are the product of individual differences (i.e., both within and between entities; Dansereau et al., 1984).

The MLQ has been in existence in various forms for about 20 years, and only now are we really beginning to look at its theoretical levels of analysis assumptions (cf. Schriesheim, Wu, \& Scandura, 2008). The extant data to date suggest that most of the MLQ scales contain items that are not measuring leader behavior at the levels of analysis that are theoretically appropriate for these constructs. We wrote our items to apply to leader-subordinate relationships at the individual level of analysis (see Appendix). However, we certainly do not want a situation similar to that of the MLQ to hold 20 years in the future with respect to our new omission scales. We therefore believe that level of analysis testing should be undertaken on these new measures as soon as possible.

We believe that the leader omission constructs are most likely to operate at the individualdifferences level. This level of operation should ameliorate possible concerns about the effects uncovered and reported in the series of studies presented here and should make our analyses fully appropriate for further investigation of the research questions and hypotheses that have been investigated. The reason for this belief is as follows. Although some leaders are likely to have more stylistic ways of dealing with their supervisory activities and responsibilities (i.e., supervisor omission behavior is likely to be at least partly a between-supervisors phenomenon), the reactions of their subordinates are likely to be colored by the subordinates' performance perceptions and attributions (i.e., subordinate outcome variables are likely to be at least partly a within-supervisors phenomenon). When these two effects are combined, the likely result is that leadership omission correlations with various outcome criteria are likely to be both a within- and a between- supervisors phenomenon. As such, the leader omission correlations would be indicative of individual differences and would make analyses such as those performed in the current research wholly appropriate (Dansereau et al., 1984). Our conceptual argument and empirical results regarding the individual level of analysis are consistent with the vast majority of transformational/ transactional literature (Yammarino, Dionne, Chun, Danserau, 2005). Obviously, the above arguments support placing some degree of confidence in the findings of our four studies but do not negate the need for empirical investigation of level of analysis effects in future research on leader omission behavior. We strongly encourage such future research.

\section{Limitations}

One issue concerning the validity of our results concerns the degree to which they are likely to be produced or distorted by common method variance (see Podsakoff et al., 2003). We specifically tested for such effects in Study 3, and, although significant common method variance effects were evident, statistically controlling for these effects did not wash out the majority of our findings. Additionally, we mention five things that should further reduce concerns about our findings being artifacts due to common method variance.

First, we used a number of procedural study design remedies that should have reduced the 
susceptibility of our data to common method bias (for example, anonymity or confidentiality and very strong assurances of protection; use of different questionnaire sections, instructions, and response scales for different measures; Podsakoff et al., 2003). Second, confirmatory factor-analytic results in the samples we used to test our nine substantive hypotheses clearly supported a four-factor model. Substantial common method variance might very well have resulted in supporting fewer factors (Podsakoff et al., 2003).

Third, two of our dependent variables (satisfaction and subordinate-perceived supervisor effectiveness) are the variables most commonly used in MLQ research (Dumdum et al., 2002), and role clarity also is frequently used in LRPQ research on contingent reward and punishment behavior (Podsakoff et al., 2006). Thus, we could determine whether our results were atypical or incongruent with the extant literature (they clearly were not).

Fourth, one of the dependent variables that we employed in Study 4 was supervisor-rated employee performance, measured 14 weeks after the employee data were collected. Our findings with this variable generally supported our hypothesis (Hypothesis 9); because common method variance could not have confounded the results, these findings increase confidence in our conclusion that the new omission variables have promise for the future study of leadership processes.

Finally, we know of no a priori reason to expect any particular type of distortion due to our sampling of respondents (but it is true that any study's results may not generalize to other settings). We utilized a total of four independent and very different samples in the development and testing of our new measures. This variance in situations, locations, and respondents can serve to ameliorate any potential context effects that may occur due to use of singlesample respondents, and it may also provide some confidence in the generalizability and robustness of our results.

\section{Conclusion}

As stated by Judge and Piccolo (2004) and supported by others (e.g., Skogstad et al., 2007), inactive or nonleadership appears important and seems to merit further study. Until now, leader reward and punishment omission have not been studied in organizational settings (Komaki, 1998). It is not clear why these potentially important dimensions have been ignored, especially as we know the benefits of positive reinforcement and contingent rewards (Podsakoff et al., 2006) and the negative effects of laissez- faire leadership (Judge \& Piccolo, 2004; Skogstad et al., 2007). It is possible that researchers and practitioners essentially adopt the philosophy of "no news is good news" in the belief that managers' nonresponse to good and poor performance would have no effect on affective responses or future behavior. This study not only has supported the importance of providing performance-contingent reinforcement but has produced evidence of the potential harm of not providing it. Thus, although this study was exploratory and was aimed at opening a new stream of research on leader omission behavior, the encouraging results clearly need replication and extension.

The rigor involved in our scale development and preliminary validation processes should increase confidence in our results and, it is hoped, stimulate others to explore the ideas that we have tried to develop here. Future research should examine levels of analysis issues and the relationship of omission behaviors and other outcomes, particularly additional indicators of managerial and subordinate performance and various affective outcomes, such as organizational commitment and perceptions of organizational justice. However, we feel that this research can serve as a useful foundation for the development of future knowledge on leader omission behavior and hope that such research will be 
forthcoming.

\section{References}

Adams, J. S. (1965). Inequity in social exchange. In L. Berkowitz (Ed.), Advances in experimental social psychology (Vol. 2, pp. 267-299). New York: Academic Press.

Antonakis, J., Avolio, B. J., \& Sivasubramaniam, N. (2003). Context and leadership: An examination of the nine-factor full-range leadership theory using the Multifactor Leadership Questionnaire. Leadership Quarterly,14, 261-295.

Avolio, B. J. (1999). Full leadership development: Building the vital forces in organizations. Thousand Oaks, CA: Sage.

Avolio, B. J., \& Bass, B. M. (1991). The full range leadership development programs: Basic and advanced manuals. New York: Bass, Avolio, \& Associates.

Avolio, B. J., Bass, B. M., \& Jung, D. I. (1999). Re-examining the components of transformational and transactional leadership using the Multifactor Leadership Questionnaire. Journal of Occupational and Organizational Psychology, 72, 441-462.

Bass, B. M. (1985). Leadership and performance beyond expectations. New York: Free Press.

Bass, B. M. (1990). Bass and Stogdill's handbook of leadership: Theory, research, and managerial applications (3rd ed.). New York: Free Press. Bass, B. M., \& Avolio, B. J. (1993). Multifactor Leadership Questionnaire.

Palo Alto, CA: Consulting Psychologists Press.

Bass, B. M., \& Avolio, B. J. (1997). Full range leadership development: Manual for the Multifactor Leadership Questionnaire. Palo Alto, CA: Mindgarden.

Bass, B. M., Avolio, B. J., Jung, D. I., \& Berson, Y. (2003). Predicting unit performance by assessing transformational and transactional leadership. Journal of Applied Psychology, 88, 207-218.

Byrne, Z. S., \& Cropanzano, R. (2001). The history of organizational justice: The founders speak. In R. Cropanzano (Ed.), Justice in the workplace: From theory to practice (Vol. 2, pp. 3-26). Mahwah, NJ: Erlbaum.

Cohen, J. (1969). Statistical power analysis for the behavioral sciences. San Diego, CA: Academic Press.

Dansereau, F., Alutto, J. A., \& Yammarino, F. J. (1984). Theory testing in organizational behavior: The "varient" approach. Englewood Cliffs, NJ: Prentice Hall.

Den Hartog, D. N., Van Muijen, J. J., \& Koopman, P. L. (1997). Transactional versus transformational leadership: An analysis of the MLQ. Journal of Occupational and Organizational Psychology, 70, 19-34. Druskat, V. U. (1994). Gender and leadership style: Transformational and transactional leadership in the Roman Catholic Church. Leadership Quarterly, 5, 99-119.

Dumdum, U. R., Lowe, K. B., \& Avolio, B. J. (2002). A meta analysis of transformational and transactional leadership. In B. J. Avolio and F. J. Yammarino (Eds.), Transformational and charismatic leadership: The road ahead (pp. 35-66). Oxford, England: Elsevier Science.

Hinkin, T. R. (1998). A brief tutorial on the development of measures for use in survey questionnaires. 
Organizational Research Methods, 1, 104-121.

Hinkin, T. R., \& Tracey. J. B. (1999). An analysis of variance approach to content validation. Organizational Research Methods, 2, 175-186. House, R. J. (1977). A 1977 theory of charismatic leadership. In J. G. Hunt

\& L. L. Larson (Eds.), Leadership: The cutting edge (pp. 189-207). Carbondale: Southern Illinois University Press.

Howell. J. P., \& Costley, D. L. (2006). Understanding behaviors for effective leadership (2nd ed.). Upper Saddle River, NY: Prentice-Hall.

Hu, L., \& Bentler, P. M. (1999). Cutoff criteria in fix indexes in covariance structure analysis: Conventional criteria versus new alternatives. Structural Equation Modeling, 6, 1-55.

Hunt, J. G. (1999). Transformational/charismatic leadership's transformation of the field: An historical essay. Leadership Quarterly, 10, 423-448.

Joreskog, K. G., \& Sorbom, D. (1999). LISREL 8.7 for Windows [Computer software]. Lincolnwood, IL: Scientific Software.

Judge, T. A., \& Piccolo, R. F. (2004). Transformational and transactional leadership: A meta-analytic test of their relative value. Journal of Applied Psychology, 89, 755-768.

Klein, K. J., Dansereau, F., \& Hall, R. J. (1994). Levels issues in theory development, data collection, and analysis. Academy of Management Review, 19, 195-229.

Komaki, J. L. (1998). Leadership from an operant perspective. New York: Routledge.

Locke, E. A. (1976). The nature and causes of job satisfaction. In M. D. Dunnette (Ed.), Handbook of industrial and organizational psychology. Chicago: Rand McNally.

Lowe, K. B., Kroeck, K. G., \& Sivasubramaniam, N. (1996). Effectiveness correlates of transformational and transactional leadership: A meta-analytic review of the MLQ literature. Leadership Quarterly, 3, 385-425.

Luthans, F., \& Kreitner, R. (1985). Organizational behavior modification and beyond. Glenview, IL: Scott, Foresman.

McNemar, Q. (1969). Psychological statistics (4th ed.). New York: Wiley.

Mott, P. E. (1972). The characteristics of effective organizations. New York: Harper.

Nunnally, J., \& Bernstein, I. (1994). Psychometric theory (3rd ed.). New York: McGraw-Hill.

Petrock, F. (1978). Analyzing the balance of consequences for performance improvement. Journal of Organizational Behavior Management, 1, 196-205.

Pithers, R. T. (1985). The roles of event contingencies and reinforcement in human autoshaping and omission responding. Learning and Motivation, 16, 210-237.

Podsakoff, P. M., Bommer, W. H., Podsakoff, N. P., \& MacKenzie, S. B. (2006). Relationships between leader reward and punishment behavior and subordinate attitudes, perceptions, and behaviors: A meta-analytic review of existing and new research. Organizational Behavior and Human Decision Processes, 99, 113-142.

Podsakoff, P. M., MacKenzie, S. B., Lee, J. Y., \& Podsakoff, N. P. (2003). Common method biases in behavioral 
research: A critical review of the literature and recommended remedies. Journal of Applied Psychology, 88, 879-903.

Podsakoff, P. M., Todor, W. D., Grover, R. A., \& Huber, V. L. (1984). Situational moderators of leader reward and punishment behaviors: Fact or fiction? Organizational Behavior and Human Performance, 34, 21-63.

Podsakoff, P. M., Todor, W. D., \& Skov, R. B. (1982). Effects of leader contingent and noncontingent reward and punishment behaviors on subordinate performance and satisfaction. Academy of Management Journal, $25,810-821$.

Rachlin, H. (1989). Judgment, decision, and choice: A cognitive/ behavioral synthesis. New York: Freeman.

Rizzo, J. R., House, R. J., \& Lirtzman, S. E. (1970). Role conflict and ambiguity in complex organizations. Administrative Science Quarterly, 15, 150-163.

Schriesheim, C. A., Castro, S. L., Zhou, X., \& Yammarino, F. J. (2001). The folly of theorizing "A" but testing " $B$ ": A selective level of analysis review of the field and a detailed leader-member exchange (LMX) illustration. Leadership Quarterly, 12, 515-551.

Schriesheim, C. A., Cogliser, C. C., Scandura, T. A., Lankau, M. J., \& Powers, K. J. (1999). An empirical comparison of approaches for quantitatively assessing the content adequacy of paper-and-pencil measurement instruments. Organizational Research Methods, 2, 140-156.

Schriesheim, C. A., Hinkin, T. R., \& Tetrault, L. A. (1991). The discriminant validity of the Leader Reward and Punishment Questionnaire (LRPQ) and satisfaction with supervision: A two sample, factor analytic investigation. Journal of Occupational Psychology, 64, 159-166.

Schriesheim, C. A., Neider, L. L., \& Scandura, T. A. (1998). A within- and between-groups analysis of leadermember exchange as a correlate of delegation and as a moderator of delegation relationships with performance and satisfaction. Academy of Management Journal, 41, 298-318.

Schriesheim, C. A., Powers, K. J., Scandura, T. A., Gardiner, C. C., \& Lankau, M. J. (1993). Improving construct measurement in management research: Comments and a quantitative approach for assessing the theoretical adequacy of paper-and-pencil and survey-type instruments. Journal of Management, 19, 385-417.

Schriesheim, C. A., Wu, J. B., \& Scandura, T. A. (2007, May). A theoretical and empirical analysis of the levels of analysis of the Multifactor Leadership Questionnaire (MLQ). Unpublished paper presented at the J. G. Hunt Leadership Festschrift, Lubbock, Texas.

Skinner, B. F. (1969). Contingencies of reinforcement: A theoretical analysis. New York: Appleton-CenturyCrofts.

Skogstad, A., Einarsen, S., Torsheim, T., Aasland, M. S., \& Hetland, H. (2007). The destructiveness of laissezfaire leadership behavior. Journal of Occupational Health Psychology, 12, 80-92.

Tejeda, M. J., Scandura, T. A., \& Pillai, R. (2001). The MLQ revisited: Psychometric properties and recommendations, Leadership Quarterly, 12, 31-52.

Thibaut, J., \& Walker, L. (1975). Procedural justice: A psychological analysis. Hillsdale, NJ: Erlbaum.

Vroom, V. H. (1964). Work and motivation. New York: Wiley. 
Weiner, B. (1985). An attribution theory of achievement and motivation,

Psychological Review, 92, 548 -573.

Weiss, D. J., Dawis, R. V., England, G. W., \& Lofquist, L. H. (1967). Manual for the Minnesota Satisfaction Questionnaire (Minnesota Studies in Vocational Rehabilitation 22). Minneapolis: Industrial Relations Center, University of Minnesota.

Widaman, K. F. (1985). Hierarchically nested covariance structure models for multitrait-multimethod data. Applied Psychological Measurement, 9, 1-26.

Williams, L., Ford, L., \& Nguyen, N. (2002). Basic and advanced measurement models for confirmatory factor analysis. In S. Rogelberg (Ed.), Handbook of research methods in industrial and organizational psychology (pp. 366-389). Oxford, England: Blackwell.

Yammarino, F. J., Dionne, S. D., Chun, J. U., \& Danserau, F. (2005). Leadership and levels of analysis: A stateof-the-science review. Leadership Quarterly, 16, 879-919.

Yukl, G. (2006). Leadership in organizations (6th ed.). Upper Saddle River, NJ: Prentice-Hall

\section{Appendix}

\section{New Omission Scale Items}

\section{Reward Omission}

1. I often perform well in my job and still receive no praise from my manager. (Item 5; reverse-scored LRPQ Item 10; 4.43)

2. My manager often gives me no feedback when I perform well. (Item 14; 4.31)

3. When I perform well my manager usually does nothing. (Item 7; 4.56)

4. My good performance often goes unacknowledged by my manager. (Item 18; reverse-scored LRPQ Item 9; 4.50)

5. I don't often get praised by my manager when I perform well. (Item 19; 4.37)

6. My good performance often gets no response from my manager. (Item 25; 4.37)

\section{Punishment Omission}

7. I seldom get criticized by my manager when I perform poorly. (Item 16; 3.97)

8. My manager gives me no feedback when I perform poorly. (Item 8; 4.24) 
9. My poor performance often goes unacknowledged by my manager. (Item 20; 4.13)

10. When I perform poorly in my job I receive no criticism from my manager. (Item 4; 4.18)

11. When I perform poorly my manager does nothing. (Item 22; 4.28)

12. My poor performance often gets no response from my manager. (Item 3; 4.27)

Note. Italicized items were not retained for subsequent analyses on the basis of the content adequacy assessment. The numbers in parentheses indicate the order in which the items appeared on the content adequacy assessment instrument and the mean content adequacy score (on a 1-5 scale) for each item on its appropriate definition. 